\title{
openheart Male-female differences in aortic valve and combined aortic valve/coronary surgery: a national cohort study in the Netherlands
}

\author{
M Mostafa Mokhles, ${ }^{1}$ Sadaf Soloukey Tbalvandany, ${ }^{1}$ Sabrina Siregar, ${ }^{2}$ \\ Michel I M Versteegh, ${ }^{2}$ Luc Noyez, ${ }^{3}$ Bart van Putte, ${ }^{4}$ Alexander B A Vonk, ${ }^{5}$ \\ Jolien W Roos-Hesselink, ${ }^{6}$ Ad J J C Bogers, ${ }^{1}$ Johanna J M Takkenberg ${ }^{1}$
}

\section{ABSTRACT}

Objective The outcome of female patients after adult cardiac surgery has been reported to be less favourable compared with the outcome of male patients. This study compares men with women with respect to patient and procedural characteristics and early mortality in a contemporary national cohort of patients who underwent aortic valve (AV) and combined aortic valve/coronary (CABG/AV) surgery.

Methods All patients who underwent AV $(\mathrm{n}=8717,56 \%$ male) or a combined CABG/AV surgery $(n=5867,67 \%$ male) in the Netherlands between January 2007 and December 2011 were included.

Results In both groups, women were generally older than men $(p<0.001)$ and presented with higher logistic EurOSCORES. In isolated AV surgery, men and women had comparable in-hospital mortality (OR 1.20, $95 \% \mathrm{Cl}$ 0.90 to $1.61 ; p=0.220$ ). In concomitant CABG/AV surgery, in-hospital mortality was higher in women compared with men (OR 2.00, 95\% Cl 1.44 to 2.79; $p<0.001$ ). The area under the curve for logistic EuroSCORE 1 was systematically higher for men versus women in isolated AV surgery $0.82(95 \% \mathrm{Cl} 0.78$ to 0.86$)$ vs $0.75(95 \% \mathrm{Cl} 0.69$ to 0.80$)$ and in concomitant $\mathrm{CABG} / \mathrm{AV}$ surgery $0.78(95 \%$ $\mathrm{Cl} 0.73$ to 0.82 ) vs 0.69 (95\% $\mathrm{Cl} 0.63$ to 0.74$)$. Finally, (the weight of) risk factors associated with in-hospital mortality differed between men and women.

Conclusions There are substantial male-female differences in patient presentation and procedural aspects in isolated $\mathrm{AV}$ and concomitant $\mathrm{CABG} / \mathrm{AV}$ surgery in the Netherlands. Further studies are necessary to explore the mechanisms underlying the observed differences. In addition, the observation that standard risk scores perform worse in women warrants exploration of male-female specific risk models for patients undergoing cardiac surgery.Brief title:

C) Author(s) (or their employer(s)) 2018. Re-use permitted under CC BY-NC. No commercial re-use. See rights and permissions. Published by BMJ.

For numbered affiliations see end of article.

Correspondence to Dr M Mostafa Mokhles; m. mokhles@erasmusmc.nl

\section{Key questions}

What is already known about this subject?

- The outcome of female patients after adult cardiac su-rgery has been reported to be less favourable compared with the outcome of male patients. Most studies addressing male-female differences have focused on coronary artery bypass graft (CABG) surgery, and little is known on outcomes in patients undergoing aortic valve (AV) surgery or concomitant $\mathrm{CABG} / \mathrm{AV}$ surgery in particular.

What does this study add?

- The observed male-female differences in presentation, procedural characteristics and treatment outcomes in isolated AV or concomitant CABG/AV surgery illustrate that male-female differences in cardiac surgery extend beyond isolated CABG and are also apparent in AV surgery. This study also accentuates the complexity of addressing male-female differences in cardiac surgery, as differences are apparent in presentation and treatment, and in outcome and risk stratification approaches.

How might this impact on clinical practice?

- Further studies are necessary to explore the mechanisms underlying the observed differences in men and women. In addition, the observation that standard risk scores perform worse in women warrants exploration of male-female specific risk models for patients undergoing cardiac surgery.

less favourable compared with the outcome of male patients. Especially, in-hospital mortality risk has been reported to be higher in female patients. ${ }^{3-11}$ In addition, there is an increasing awareness of the male-female differences in the timing of diagnosis in the disease process, as well as the disease presentation. ${ }^{12}$ Most studies addressing male-female differences have focused on coronary artery bypass graft (CABG) surgery, and little 
is known on outcomes in patients undergoing aortic valve (AV) surgery or concomitant CABG/AV surgery. ${ }^{3-11} 13$

Exploration of male-female differences in patient and procedural characteristics in adult AV and concomitant CABG/AV surgery will allow better insight in potential differences in disease presentation, surgical treatment and early survival between male and female patients, and will provide valuable information towards a more effective approach of modifiable risk factors.

The objective of the present study was, therefore, to compare adult men with women with respect to preoperative and procedural characteristics, risk factors and short-term outcome in a contemporary national Dutch cohort of patients who underwent AV or concomitant CABG/AV surgery.

\section{METHODS}

\section{Source of study data}

The national database of The Netherlands Association for Cardio-Thoracic Surgery was used for this study. The prospective database contains data on all cardiac surgery procedures performed in the Netherlands since 1 January 2007. Procedures were included in the database if open heart surgery was performed in a patient of $>18$ years. Open heart surgery is defined by a surgical intervention to the heart with opening of the pericardium. The data set included the date and type of intervention, anonymised patient information, risk factors and outcomes. The risk factors for cardiac mortality were defined according to the EuroSCORE 1 model. ${ }^{14} \mathrm{~A}$ detailed description of the database has been published previously. ${ }^{15}$

\section{Study population}

A total of 134.039 cardiac surgery procedures were performed in the Netherlands between 1 January 2007 and 31 December 2011. Procedures were considered for inclusion if they involved patients $>18$ years who underwent isolated AV surgery $(\mathrm{n}=8717)$ or concomitant $\mathrm{CABG} / \mathrm{AV}$ surgery $(\mathrm{n}=5867)$. Baseline characteristics of these patient groups can be found in tables 1 and 2.

Table 1 Baseline variable patients with isolated AV surgery

\begin{tabular}{|c|c|c|c|c|}
\hline Characteristics & $\begin{array}{l}\text { Total AV cohort } \\
(\mathrm{n}=8717) \\
\mathrm{n}(\%)\end{array}$ & $\begin{array}{l}\text { Male } \\
(n=4888,56 \%) \\
n(\%)\end{array}$ & $\begin{array}{l}\text { Female } \\
(n=3829,44 \%) \\
n(\%)\end{array}$ & $P$ values \\
\hline Age & $68.5 \pm 11.8(18-94)$ & $66.2 \pm 12.0(18-93)$ & $71.4 \pm 10.9(19-94)$ & $<0.001$ \\
\hline Chronic lung disease & 1209 (13.9) & $707(14.5)$ & $502(13.1)$ & 0.074 \\
\hline Extracardiac arteriopathy & $699(8.0)$ & $443(9.7)$ & $256(6.7)$ & $<0.001$ \\
\hline Neurological dysfunction & $244(2.8)$ & $142(2.9)$ & $102(2.7)$ & 0.498 \\
\hline Prior cardiac surgery & $867(9.9)$ & $603(12.3)$ & $264(6.9)$ & $<0.001$ \\
\hline $\begin{array}{l}\text { Serum creatinine (>200 } \\
\mu \mathrm{m} / \mathrm{L})\end{array}$ & $149(1.7)$ & $111(2.3)$ & $38(1.0)$ & $<0.001$ \\
\hline Active endocarditis & $354(4.1)$ & $290(5.9)$ & $64(1.7)$ & $<0.001$ \\
\hline Critical preoperative state & $181(2.1)$ & $122(2.5)$ & $59(1.5)$ & 0.002 \\
\hline Unstable angina & $18(0.2)$ & $15(0.3)$ & $3(0.1)$ & 0.020 \\
\hline \multicolumn{5}{|l|}{ LV function } \\
\hline Good & $7284(83.6)$ & $3918(80.2)$ & 3366 (87.9) & \\
\hline Moderate & $1160(13.3)$ & $760(15.5)$ & $400(10.4)$ & \\
\hline Poor & $268(3.1)$ & $207(4.2)$ & $61(1.6)$ & \\
\hline Recent myocardial infarction & $108(1.2)$ & $67(1.4)$ & $41(1.1)$ & 0.209 \\
\hline Pulmonary hypertension & $256(2.9)$ & $142(2.9)$ & $114(3.0)$ & 0.843 \\
\hline Emergent surgery & $214(2.5)$ & $156(3.2)$ & $58(1.5)$ & $<0.001$ \\
\hline Surgery on thoracic aorta & $0(0.0)$ & $0(0.0)$ & $0(0.0)$ & \\
\hline Postinfarct septal rupture & $0(0.0)$ & $0(0.0)$ & $0(0.0)$ & \\
\hline Prior $\mathrm{PCl}$ & $363(4.2)$ & $231(4.7)$ & $132(3.4)$ & 0.002 \\
\hline Prior CABG & $377(4.3)$ & $283(5.8)$ & $94(2.5)$ & $<0.001$ \\
\hline Prior valve surgery & $372(4.3)$ & $237(4.8)$ & $135(3.5)$ & 0.002 \\
\hline Prior aorta surgery & $41(0.5)$ & $237(4.8)$ & $135(3.5)$ & 0.197 \\
\hline Prior other cardiac surgery & $232(2.7)$ & $121(2.5)$ & $111(2.9)$ & 0.247 \\
\hline
\end{tabular}

Significant values are depicted in bold.

$\mathrm{AV}$, aortic valve; CABG, coronary artery bypass graft; LV, left ventricular; $\mathrm{PCI}$, percutaneous coronary intervention. 
Table 2 Baseline variable patients with concomitant CABG/AV surgery

\begin{tabular}{|c|c|c|c|c|}
\hline Characteristics & $\begin{array}{l}\text { Total CABG/AV cohort } \\
(\mathrm{n}=5867) \\
\mathrm{n}(\%)\end{array}$ & $\begin{array}{l}\text { Male } \\
(n=3937,67 \%) \\
n(\%)\end{array}$ & $\begin{array}{l}\text { Female } \\
(n=1928,33 \%) \\
n(\%)\end{array}$ & $P$ values \\
\hline Age & $72.8 \pm 8.2(31-94)$ & $71.7 \pm 8.2(31-93)$ & $75.0 \pm 7.5(33-94)$ & $<0.001$ \\
\hline Chronic lung disease & $894(15.2)$ & $660(16.8)$ & $234(12.1)$ & $<0.001$ \\
\hline Extracardiac arteriopathy & $992(16.9)$ & $743(18.9)$ & $249(12.9)$ & $<0.001$ \\
\hline Neurological dysfunction & $181(3.1)$ & $136(3.5)$ & $45(2.3)$ & $<0.001$ \\
\hline Prior cardiac surgery & $250(4.3)$ & $186(4.7)$ & $64(3.3)$ & $<0.001$ \\
\hline Serum creatinine $(>200 \mu \mathrm{m} / \mathrm{L})$ & $132(2.2)$ & $105(2.7)$ & $27(1.4)$ & $<0.001$ \\
\hline Active endocarditis & $48(0.8)$ & $41(1.0)$ & $7(0.4)$ & $<0.001$ \\
\hline Critical preoperative state & $108(1.8)$ & $73(1.9)$ & $35(1.8)$ & 0.918 \\
\hline Unstable angina & $148(2.5)$ & $95(2.4)$ & $53(2.7)$ & 0.440 \\
\hline \multicolumn{5}{|l|}{ LV function } \\
\hline Good & $4463(76.1)$ & $2878(73.1)$ & $1583(82.1)$ & \\
\hline Moderate & $1128(19.2)$ & $833(21.2)$ & $295(15.3)$ & $<0.001$ \\
\hline Poor & $274(4.7)$ & $225(5.7)$ & $49(2.5)$ & $<0.001$ \\
\hline Recent myocardial infarction & $368(6.3)$ & $256(6.5)$ & $112(5.8)$ & 0.305 \\
\hline Pulmonary hypertension & $176(3.0)$ & $110(2.8)$ & $65(3.4)$ & 0.222 \\
\hline Emergent surgery & $121(2.1)$ & $77(2.0)$ & $44(2.3)$ & 0.408 \\
\hline Surgery on thoracic aorta & $0(0.0)$ & $0(0.0)$ & $0(0.0)$ & \\
\hline Postinfarct septal rupture & $0(0.0)$ & $0(0.0)$ & $0(0.0)$ & \\
\hline Prior PCl & $532(9.1)$ & $388(9.9)$ & $144(7.5)$ & 0.002 \\
\hline Prior CABG & $172(2.9)$ & $131(3.3)$ & $41(2.1)$ & 0.010 \\
\hline Prior valve surgery & $60(1.0)$ & $131(3.3)$ & $41(2.1)$ & 0.447 \\
\hline Prior aorta surgery & $13(0.2)$ & $11(0.3)$ & $2(0.1)$ & 0.178 \\
\hline Prior other cardiac surgery & $137(2.3)$ & $106(2.7)$ & $31(1.6)$ & 0.009 \\
\hline
\end{tabular}

Significant values are depicted in bold.

$\mathrm{AV}$, aortic valve; $\mathrm{CABG}$, coronary artery bypass graft; LV, left ventricular; $\mathrm{PCl}$, percutaneous coronary intervention.

\section{Study design}

This is a retrospective cohort study of prospectively collected data from all consecutive adult cardiac surgery procedures in the Netherlands. Male-female differences in adult cardiac surgery may be due to sex (the anatomy of an individual's reproductive system, and secondary sex characteristics) or due to gender, which can refer to either social roles based on the sex of a person (gender role) or personal identification of one's own gender based on an internal awareness (gender identity), or a combination of both. In this study we therefore employ the term male-female differences and avoid the term gender, as the database only provided us with data on sex.

\section{EurOSCORE}

The EuroSCORE 1 was calculated based on a set of predefined preoperative risk factors. ${ }^{14} 16$ The additive and logistic EuroSCORE 1 models were applied to all patients undergoing cardiac surgery.

\section{Study outcome}

The outcome of interest in the present study was differences in preoperative and procedural characteristics and in-hospital mortality between male and female patients after isolated AV surgery or concomitant $\mathrm{CABG} / \mathrm{AV}$ surgery. In addition, risk factors for in-hospital mortality were explored for male and female patients separately.

\section{Statistical analyses}

Continuous data are presented as means (SD; range), and comparison was done using the unpaired t-test unless the data were not normally distributed (Kolmogorov-Smirnov test); in these instances, we used the Mann-Whitney U test for comparison. Categorical data are presented as proportions, and comparison was done using the $\mathrm{X}^{2}$ test or the Fisher exact test where appropriate. Binary logistic regression analysis was used in both univariable and multivariable modelling to identify independent variables associated with in-hospital mortality. The following model-building strategy was used. Univariable analysis using logistic regression was used to identify variables that were significantly associated with the outcome of interest in-hospital mortality. All independent variables with a significance level of 0.05 or less were entered in the multivariable analysis using the backward stepwise method. 
ORs are reported with associated 95\% CIs. Correlation between variables was assessed with Pearson or Spearman correlation coefficient, whenever appropriate. In case of significant correlation, the clinically most important variable was chosen to be included in the model.

Model discrimination (statistical accuracy) of the EuroSCORE 1 was tested with the receiver operating characteristic curve. ${ }^{17}$ Model calibration (statistical precision) of the EuroSCORE 1 was determined with Hosmer-Lemeshow goodness-of-fit statistic. ${ }^{18}$ The interpretation of Hosmer-Lemeshow goodness-of-fit statistic is that well-fitted models show non-significance, indicating that model prediction is not significantly different from observed values.

All statistical tests were two sided, and a $p$ value of 0.05 was used to establish statistical significance. All statistical analyses were performed using SPSS (V.20, IBM).

\section{Missing values}

Data completeness for the perioperative data in The Netherlands Association for Cardio-Thoracic Surgery database is exceptionally high. For approximately $99 \%$ of the cases included in the database the data were complete. However, there were some variables with regard to patients' history which had more missing data. Therefore, multiple imputation method was used to account for missing values in the present study. Five multiple imputation data sets were created for each subgroup using SPSS software. The imputation model included all baseline variables available. The multiple imputation data sets were used for binary logistic regression analysis in order to identify independent variables associated with in-hospital mortality.

\section{RESULTS}

Preoperative and procedural characteristics AV surgery

Of the total 8717 AV surgeries $(98.8 \%$ replacement, $1.2 \%$ reconstruction), $56 \%$ were male and $44 \%$ were female. Female patients were generally older (mean age, 71 vs 66 years, $\mathrm{p}<0.001$ ). Perioperative patient characteristics are shown in.().(table 1 and 3 )

online supplementary tables 1 and 2 display univariable and multivariable analyses of factors associated with increased hospital mortality.

\section{CABG/AV surgery}

Of the 5867 patients who underwent AV surgery with concomitant CABG $(99.1 \%$ concerned replacements and $0.9 \%$ reconstructions), $67 \%$ were male and $33 \%$ were female. Female patients were generally older (mean age, 75 vs 72 years, $\mathrm{p}<0.001)$. Perioperative patient characteristics are shown in.() (table 2 and 4 ).

Online supplementary tables 3 and 4 display univariable and multivariable analyses of factors associated with increased hospital mortality.

\section{In-hospital mortality, EuroSCORE performance and separate male-female risk factor analyses}

AV surgery

In-hospital mortality was $2.1 \%(\mathrm{n}=184)$. Female patients had comparable in-hospital mortality with male patients (OR $1.20,95 \%$ CI 0.90 to $1.61 ; \mathrm{p}=0.220$ ) as displayed in table 3 .

In men, the area under the curve (AUC) for the logistic EuroSCORE 1 was 0.82 (95\% CI 0.78 to 0.86 ) vs 0.75 ( $95 \%$ CI 0.69 to 0.80$)$ in women. The calibration of the

\begin{tabular}{|c|c|c|c|c|}
\hline Characteristics & $\begin{array}{l}\text { Total AV cohort } \\
(\mathrm{n}=8717) \\
\mathrm{n}(\%)\end{array}$ & $\begin{array}{l}\text { Male } \\
(n=4888,56 \%) \\
n(\%)\end{array}$ & $\begin{array}{l}\text { Female } \\
(n=3829,44 \%) \\
n(\%)\end{array}$ & P values \\
\hline Type of procedure & & & & $<0.001$ \\
\hline Repair & $105(1.2)$ & $77(1.6)$ & $28(0.7)$ & \\
\hline Replacement & 8612 (98.8) & 4811 (98.4) & 3801 (99.3) & \\
\hline \multicolumn{5}{|l|}{ Type of implant } \\
\hline Bioprosthesis unstented & $399(4.6)$ & $166(3.4)$ & $233(6.1)$ & $<0.001$ \\
\hline Bioprosthesis stented & 5485 (62.9) & 2855 (58.4) & $2630(68.7)$ & $<0.001$ \\
\hline Mechanical & 2718 (31.2) & 1785 (36.5) & $933(24.4)$ & $<0.001$ \\
\hline Homograft & $10(0.1)$ & $5(0.1)$ & $5(0.1)$ & $<0.001$ \\
\hline \multicolumn{5}{|l|}{ EurOSCORE } \\
\hline Additive EuroSCORE & $6.2 \pm 2.7(0-23)$ & $5.7 \pm 2.9(0-23)$ & $6.9 \pm 2.4(1-22)$ & $<0.001$ \\
\hline Logistic EuroSCORE & $7.8 \pm 8.8(1-95)$ & $7.1 \pm 9.2(1-95)$ & $8.7 \pm 8.3(1-92)$ & $<0.001$ \\
\hline \multicolumn{5}{|l|}{ Outcome } \\
\hline Hospital mortality & $184(2.1)$ & $95(1.9)$ & $89(2.3)$ & 0.220 \\
\hline
\end{tabular}

Significant values are depicted in bold.

AV, aortic valve. 
Table 4 Procedural variable patients with concomitant CABG/AV surgery

\begin{tabular}{|c|c|c|c|c|}
\hline Characteristics & $\begin{array}{l}\text { Total CABG/AV cohort } \\
(\mathrm{n}=5867) \\
\mathrm{n}(\%)\end{array}$ & $\begin{array}{l}\text { Male } \\
(n=3937) \\
n(\%)\end{array}$ & $\begin{array}{l}\text { Female } \\
(n=1928) \\
n(\%)\end{array}$ & $\mathbf{P}$ values \\
\hline Type of procedure & & & & 0.168 \\
\hline Repair & $50(0.9)$ & $29(0.7)$ & $21(1.1)$ & \\
\hline Replacement & 5815 (99.1) & 3908 (99.3) & 1907 (98.9) & \\
\hline Type of implant & & & & $<0.001$ \\
\hline Bioprosthesis unstented & $259(4.4)$ & $157(4.0)$ & $100(5.2)$ & \\
\hline Bioprosthesis stented & 4465 (76.1) & $2896(73.6)$ & $1568(81.3)$ & \\
\hline Bioprosthesis unknown & $1093(18.6)$ & $0(0.0)$ & $1(0.1)$ & \\
\hline Mechanical & $238(4.1)$ & $853(21.7)$ & $238(12.3)$ & \\
\hline Homograft & $2(0.03)$ & $2(0.1)$ & $0(0.0)$ & \\
\hline Autograft & $0(0.0)$ & $0(0.0)$ & $0(0.0)$ & \\
\hline \multicolumn{5}{|l|}{ Type of graft } \\
\hline Total arterial graft & $1456(24.8)$ & $902(22.9)$ & $554(28.7)$ & $<0.001$ \\
\hline Total venous graft & $1613(27.5)$ & 1035 (26.3) & $578(30.0)$ & $<0.001$ \\
\hline Utilisation of both arterial and venous graft & $2794(47.6)$ & $1999(50.8)$ & $795(41.2)$ & $<0.001$ \\
\hline \multicolumn{5}{|l|}{ EuroSCORE } \\
\hline Additive EuroSCORE & $6.9 \pm 2.6(0-20)$ & $6.5 \pm 2.6(0-20)$ & $7.8 \pm 2.3(3-20)$ & $<0.001$ \\
\hline Logistic EuroSCORE & $9.0 \pm 8.9(1-87)$ & $8.2 \pm 8.9(1-85)$ & $10.5 \pm 8.6(2-87)$ & $<0.001$ \\
\hline \multicolumn{5}{|l|}{ Outcome } \\
\hline Hospital mortality & $134(3.4)$ & $105(5.4)$ & $239(4.1)$ & $<0.001$ \\
\hline
\end{tabular}

Significant values are depicted in bold.

$\mathrm{AV}$, aortic valve; CABG, coronary artery bypass graft.

logistic EuroSCORE 1 model resulted in p values of 0.002 and 0.0033 for men and women, respectively.

Univariate logistic regression analyses revealed several patient and procedure-related characteristics which were correlated with higher in-hospital mortality (online supplementary table 1 ). Multivariable logistic regression analysis showed that female patients were not associated with substantially higher risk of in-hospital mortality as compared with male patients. Online supplementary table 2 provides an overview of factors found to be associated with the outcome of male and female patients.

\section{CABG/AV surgery}

In-hospital mortality was $4.1 \% \quad(\mathrm{n}=239)$ and higher in female compared with male patients (OR 2.00, 95\% CI 1.44 to $2.79 ; \mathrm{p}<0.001)$ as displayed in table 4 .

In men, the AUC for the logistic EuroSCORE 1 was 0.78 (95\% CI 0.73 to 0.82 ) vs 0.69 (95\% CI 0.63 to 0.74 ) in women. The calibration of the logistic EuroSCORE 1 model resulted in $p$ values of $<0.001$ and 0.09 for men and women, respectively.

Univariate logistic regression analyses revealed several patient and procedure-related characteristics which were correlated with higher in-hospital mortality (online supplementary table 3). Multivariable logistic regression analysis showed that female patients were still associated with substantially higher risk of in-hospital mortality as compared with male patients $(2.00,95 \%$ CI 1.44 to 179 ; $\mathrm{p}<0.001)$.

Online supplementary table 4 summarises the risk factors that were found to be associated with the outcome of male and female patients.

\section{DISCUSSION}

The observed male-female differences in presentation, procedural characteristics and treatment outcomes in isolated $\mathrm{AV}$ or concomitant $\mathrm{CABG} / \mathrm{AV}$ surgery illustrate that male-female differences in cardiac surgery extend beyond isolated $\mathrm{CABG}$ and are also apparent in $\mathrm{AV}$ surgery. This study also accentuates the complexity of addressing male-female differences in cardiac surgery, as differences are apparent in presentation and treatment, and in outcome and risk stratification approaches.

In this discussion, we will address key findings for the two surgical treatments separately, the limitations of standard risk models and potential further studies that may help optimise cardiac surgery treatment for both men and women.

\section{AV surgery}

Our analysis showed that in-hospital mortality for AV surgery was comparable between male and female patients. The AUC for the logistic EuroSCORE 1 was 
larger in men than in women, indicating that this model is a better predictor of outcome for men. Our findings confirm the results of earlier studies where no male-female differences in mortality outcome and non-cardiac morbidity were found. ${ }^{19-23}$ In contrast, Andrei et $a l^{24}$ found that women with bicuspid AVs undergoing $\mathrm{AV}$ surgery were at a higher risk of in-hospital mortality. Short-term (30 days) and long-term mortality, however, appeared to be similar.

\section{CABG/AV surgery}

For concomitant CABG/AV surgery, in-hospital morality was significantly higher in women than in men in the present study. Again, the AUC for the logistic EuroSCORE 1 was larger in men than in women, indicating that this model is a better predictor of outcome for men. Doenst $e t$ $a l^{25}$ reported a higher perioperative risk profile in women undergoing concomitant valve and CABG surgery and found the following risk factors to be associated with higher perioperative mortality in women: hypertension, diabetes mellitus, congestive heart failure, atrium fibrillation and stroke. None of these factors appeared to show a significant association with higher female in-hospital mortality in our study. Similar to our findings, Flameng et $a t^{26}$ reported female sex, in addition to patient age, to be an independent preoperative risk factor of early mortality in concomitant valve and CABG surgery. This observation was not found by Saxena $e t a l . .^{27}$ The authors report a mean age of 76 in women in their cohort and argue that their results may reflect the impact of advanced age in reducing male-female bias.

Interestingly, in line with the current literature, ${ }^{2425}$ 27-29 we also found female patients to be older in both surgical groups, which might explain why in both groups, women received significantly less often a mechanical valve and more often stented and stentless bioprosthesis as compared with men. This age difference in male versus female patients could also fuel speculations concerning later presentation of female patients in the disease process or even higher levels of frailty at time of presentation, potentially explaining the worse outcomes in female patients after $\mathrm{CABG} / \mathrm{AV}$ surgery.

Based on our results, we could additionally speculate whether the observed differences in male-female outcomes after CABG/AV surgery are due to other possible risk factors not included in the current study, including genetic or hormonal risk factors specific for women. These potential risk factors form a separate challenge altogether given the complexity of the potential underlying mechanisms. Therefore, future studies in these domains are warranted to unravel other potential female-specific risk factors after cardiac surgery.

\section{EuroSCORE}

Although EuroSCORE 1 is one of the most widely used cardiac surgical risk models, several studies have shown during the last decade that it overpredicts patient mortality and is no longer appropriately calibrated.
In our study for both groups, the performance of the EuroSCORE 1 in men and women, both in terms of accuracy and calibration, is suboptimal. In addition, the accuracy of the model was inferior in female patients in both subgroups. This observation might be explained by the fact that $72 \%$ of the original EuroSCORE population was male. Although EuroSCORE 1 includes woman versus man as a separate risk factor, it has been shown that a female-specific weighing of the other 16 risk factors that are included in EuroSCORE 1 is needed for adequate prediction of outcome in female patients. ${ }^{30}$

\section{Gender-specific risk prediction models}

In our patient population there were only a few risk factors, which are included in EuroSCORE 1, predictive of short-term mortality in both male and female patients. In this regard, male and female-specific risk prediction models are needed for patients undergoing cardiac surgery. More recently, the new EuroSCORE 2 has been developed. ${ }^{14}$ Although improvements have been made with this updated model, the risk score was again built using a mixed population of male and female patients who underwent predominantly CABG surgery. Future studies need to clarify whether the performance of this updated model is also adequate in female patients.

The observed differences in (the weight of) risk factors between men and women in the predictive in-hospital mortality models that we constructed for men and women separately underline the need for further refinement of current prediction models in cardiac surgery. Probably, the best approach will be to develop, next to generic models such as EuroSCORE 2 that are mainly useful for benchmarking purposes, separate risk models for men and women in order to improve predictive ability for both sexes, but also to further stimulate research into the causes of the observed differences between men and women, be it sex, gender or a combination of the two.

\section{Future recommendations}

Further studies need to focus on exploration of the underlying mechanisms of the observed male-female differences in presentation, procedure and early mortality in order to optimise treatment for both male and female AV and combined CABG/AV surgery.

Given the significantly worse outcome in women compared with men for combined CABG/AV surgery, underlying factors contributing to worse disease outcome should be further investigated. Especially interesting are the effect of possible referral bias, atypical female presentation and/or differences in procedural characteristics for women on female outcomes as compared with men.

Finally, given the literature, there seems to be an age effect in the observed male-female differences, further studies zooming in on the intersection of age and male-female differences, especially the treatment of younger female patients, are warranted. 


\section{Strengths and limitations}

The main strength of this study is that we were able to use a large contemporary national database with high-quality information (99\% completeness) about all cardiac surgical interventions from all hospitals in the Netherlands. The major limitation of the current study, inherent to the type of database used, is the absence of detailed information regarding the disease aetiology, the absence of information on survival beyond hospital stay.

\section{Author affiliations}

${ }^{1}$ Department of Cardiothoracic Surgery, Erasmus University Medical Center, Rotterdam, The Netherlands

${ }^{2}$ Department of Cardiothoracic Surgery, Leiden University Medical Center, Leiden, The Netherlands

${ }^{3}$ Department of Cardiothoracic Surgery, Radboud University Medical Center, Nijmegen, The Netherlands

${ }^{4}$ Department of Cardiothoracic Surgery, St Antonius Hospital, Nieuwegein, The Netherlands

${ }^{5}$ Department of Cardiothoracic Surgery, Free University Medical Center, Amsterdam, The Netherlands

${ }^{6}$ Department of Congenital Cardiology, Erasmus University Medical Center, Rotterdam, The Netherlands

Contributors MMM and JJMT were involved in the conception of the work. MMM was involved in data collection. MMM, SST and JJMT were involved in data analysis and interpretation. MMM and SST were involved in drafting the article. All authors were involved in critical revision of the article as well as in final approval of the version to be published.

Funding This work was supported by a NWO Veni grant of the Netherlands Organisation for Scientific Research [NWO grant number 916.160.87] to [MM].

Competing interests This research was conducted on behalf of the data registry committee of the Netherlands Association for Cardio-Thoracic Surgery.

Patient consent Not required.

Provenance and peer review Not commissioned; externally peer reviewed.

Open access This is an Open Access article distributed in accordance with the Creative Commons Attribution Non Commercial (CC BY-NC 4.0) license, which permits others to distribute, remix, adapt, build upon this work non-commercially, and license their derivative works on different terms, provided the original work is properly cited and the use is non-commercial. See: http://creativecommons.org/ licenses/by-nc/4.0

\section{REFERENCES}

1. Go AS, Mozaffarian D, Roger VL, et al. Heart disease and stroke statistics--2013 update: a report from the American Heart Association. Circulation 2013;127:e6-e245.

2. Bridgewater B, Kinsman R, Walton P, et al. The 4th European Association for Cardio-Thoracic Surgery adult cardiac surgery database report. Interact Cardiovasc Thorac Surg 2011;12:4-5.

3. Woods SE, Noble G, Smith JM, et al. The influence of gender in patients undergoing coronary artery bypass graft surgery: an eight-year prospective hospitalized cohort study. J Am Coll Surg 2003;196:428-34.

4. Vaccarino V, Abramson JL, Veledar E, et al. Sex differences in hospital mortality after coronary artery bypass surgery: evidence for a higher mortality in younger women. Circulation 2002;105:1176-81.

5. Zitser-Gurevich Y, Simchen E, Galai N, et al. Effect of perioperative complications on excess mortality among women after coronary artery bypass: the Israeli Coronary Artery Bypass Graft Study (ISCAB). J Thorac Cardiovasc Surg 2002;123:517-24.

6. Brandrup-Wognsen G, Berggren $\mathrm{H}$, Hartford M, et al. Female sex is associated with increased mortality and morbidity early, but not late, after coronary artery bypass grafting. Eur Heart $J$ 1996;17:1426-31.
7. Hogue CW, Barzilai B, Pieper KS, et al. Sex differences in neurological outcomes and mortality after cardiac surgery: a society of thoracic surgery national database report. Circulation 2001;103:2133-7.

8. King KB, Clark PC, Hicks GL. Patterns of referral and recovery in women and men undergoing coronary artery bypass grafting. $A m \mathrm{~J}$ Cardiol 1992;69:179-82.

9. Edwards FH, Carey JS, Grover FL, et al. Impact of gender on coronary bypass operative mortality. Ann Thorac Surg 1998;66:125-31.

10. Jacobs AK, Kelsey SF, Brooks MM, et al. Better outcome for women compared with men undergoing coronary revascularization: a report from the bypass angioplasty revascularization investigation (BARI). Circulation 1998;98:1279-85.

11. Mokhles MM, Siregar S, Versteegh MI, et al. Male-female differences and survival in patients undergoing isolated mitral valve surgery: a nationwide cohort study in the Netherlands. Eur J Cardiothorac Surg 2016;50:482-7.

12. Maas AH, Appelman YE. Gender differences in coronary heart disease. Neth Heart J 2010;18:598-603.

13. Blankstein R, Ward RP, Arnsdorf M, et al. Female gender is an independent predictor of operative mortality after coronary artery bypass graft surgery: contemporary analysis of 31 Midwestern hospitals. Circulation 2005;112(9 Suppl):I323-7.

14. Nashef SAM, Roques F, Michel P, et al. European system for cardiac operative risk evaluation (EuroSCORE). European Journal of CardioThoracic Surgery 1999;16:9-13.

15. Siregar S, Groenwold RH, Versteegh Ml, et al. Data Resource Profile: adult cardiac surgery database of the Netherlands Association for Cardio-Thoracic Surgery. Int J Epidemiol 2013;42:142-9.

16. Roques F, Michel P, Goldstone AR, et al. The logistic EuroSCORE. Eur Heart J 2003;24:882-2.

17. Hanley JA, McNeil BJ. The meaning and use of the area under a receiver operating characteristic $(\mathrm{ROC})$ curve. Radiology 1982;143:29-36.

18. Lemeshow S, Hosmer DW. A review of goodness of fit statistics for use in the development of logistic regression models. Am J Epidemiol 1982;115:92-106.

19. Duncan Al, Lin J, Koch CG, et al. The impact of gender on in-hospital mortality and morbidity after isolated aortic valve replacement. Anesth Analg:2006;103:800-8.

20. Caballero-Borrego J, Gómez-Doblas JJ, Valencia-Serrano FM, et al. [Influence of sex on perioperative outcomes in patients undergoing valve replacement for severe aortic stenosis]. Rev Esp Cardiol 2009;62:31-8.

21. Stamou SC, Robich M, Wolf RE, et al. Effects of gender and ethnicity on outcomes after aortic valve replacement. $J$ Thorac Cardiovasc Surg 2012;144:486-92.

22. Hamed O, Persson PJ, Engel AM, et al. Gender differences in outcomes following aortic valve replacement surgery. Int J Surg 2009;7:214-7.

23. Bech-Hanssen O, Wallentin I, Houltz E, et al. Gender differences in patients with severe aortic stenosis: impact on preoperative left ventricular geometry and function. as well as early postoperative morbidity and mortality.

24. Andrei AC, Yadlapati A, Malaisrie SC, et al. Comparison of outcomes and presentation in men-versus-women with bicuspid aortic valves undergoing aortic valve replacement. Am J Cardiol:2015;116:250-

25. Doenst T, Ivanov J, Borger MA, et al. Sex-specific long-term outcomes after combined valve and coronary artery surgery. Ann Thorac Surg 2006;81:1632-6.

26. Flameng WJ, Herijgers P, Szécsi J, et al. Determinants of early and late results of combined valve operations and coronary artery bypass grafting. Ann Thorac Surg 1996;61:621-8.

27. Saxena A, Poh CL, Dinh DT, et al. Does patient gender affect outcomes after concomitant coronary artery bypass graft and aortic valve replacement? An Australian Society of Cardiac and Thoracic Surgeons Database study. Cardiology:2011;119:116-.

28. Fuchs C, Mascherbauer J, Rosenhek R, et al. Gender differences in clinical presentation and surgical outcome of aortic stenosis. Heart 2010;96:539-45.

29. Girrbach F, Etz CD, Dohmen PM, et al. Longevity after mechanical aortic root replacement--do men live longer? J Thorac Cardiovasc Surg:2014;148:2087-.

30. Massoudy P, Sander J, Wendt D, et al. Does the euroSCORE equally well predict perioperative cardiac surgical risk for men and women? Minim Invasive Ther Allied Technol 2011;20:67-71. 